\title{
Induction of tumor-specific acquired immunity against already established tumors by selective stimulation of innate DEC-205 ${ }^{+}$ dendritic cells
}

\author{
Keiichi Moriya $\cdot$ Ayako Wakabayashi · \\ Masumi Shimizu $\cdot$ Hideto Tamura $\cdot$ Kazuo Dan • \\ Hidemi Takahashi
}

Received: 23 July 2009 / Accepted: 16 February 2010 / Published online: 10 March 2010

(C) The Author(s) 2010. This article is published with open access at Springerlink.com

\begin{abstract}
Two major distinct subsets of dendritic cells (DCs) are arranged to regulate our immune responses in vivo; $33 \mathrm{D} 1^{+}$and DEC-205 ${ }^{+}$DCs. Using anti-33D1-specific monoclonal antibody, 33D1 ${ }^{+}$DCs were successfully depleted from C57BL/6 mice. When 33D1 $1^{+}$DC-depleted mice were stimulated with LPS, serum IL-12, but not IL-10 secretion that may be mediated by the remaining DEC- $205^{+}$ DCs was markedly enhanced, which may induce Th1 dominancy upon TLR signaling. The 33D $1^{+} \mathrm{DC}$-depleted mice, implanted with syngeneic Hepa1-6 hepatoma or B16-F10 melanoma cells into the dermis, showed apparent inhibition of already established tumor growth in vivo when they were subcutaneously (sc) injected once or twice with LPS after tumor implantation. Moreover, the development of lung metastasis of B16-F10 melanoma cells injected intravenously was also suppressed when $33 \mathrm{D}^{+}$DC-deleted mice were stimulated twice with LPS in a similar manner, in which the actual cell number of NK1.1 ${ }^{+} \mathrm{CD} 3^{-} \mathrm{NK}$ cells in lung tissues was markedly increased. Furthermore, intraperitoneal (ip) administration of a very small amount of melphalan (L-phenylalanine mustard; L-PAM) $(0.25 \mathrm{mg} / \mathrm{kg})$ in LPS-stimulated $33 \mathrm{D} 1^{+}$DC-deleted mice helped to induce $\mathrm{H}-2 \mathrm{~K}^{\mathrm{b}}$-restricted epitope-specific $\mathrm{CD} 8^{+}$cytotoxic $\mathrm{T}$
\end{abstract}

K. Moriya and A. Wakabayashi contributed equally to this work.

K. Moriya $\cdot$ A. Wakabayashi $\cdot$ M. Shimizu $\cdot$ H. Takahashi $(\bowtie)$

Department of Microbiology and Immunology,

Nippon Medical School, 1-1-5 Sendagi,

Bunkyo-ku, Tokyo 113-8602, Japan

e-mail: htkuhkai@nms.ac.jp

K. Moriya $\cdot$ H. Tamura $\cdot$ K. Dan

Third Department of Internal Medicine,

Nippon Medical School, Tokyo 113-8602, Japan lymphocytes (CTLs) among tumor-infiltrating lymphocytes against already established syngeneic E.G7-OVA lymphoma. These findings indicate the importance and effectiveness of selective targeting of a specific subset of DCs, such as DEC-205 ${ }^{+}$DCs alone or with a very small amount of anticancer drugs to activate both $\mathrm{CD} 8^{+} \mathrm{CTLs}$ and NK effectors without externally added tumor antigen stimulation in vivo and provide a new direction for tumor immunotherapy.

Keywords 33D1 - DEC-205 - DC · Innate immunity · Acquired immunity $\cdot$ CTL

\section{Introduction}

Tumor cells develop from normal cells through several genetic transformation steps. Thus, transformed tumor cells express characteristic cell antigens that may activate various tumor-specific immune effectors. Among those effectors, $\mathrm{CD}^{+}$cytotoxic $\mathrm{T}$ lymphocytes (CTLs), which specifically recognize tumor-derived peptide epitopes presented on their surface in association with class I MHC molecule are the most potent effectors and such tumor epitope-specific $\mathrm{CD} 8^{+} \mathrm{CTLs}$ can be primed in vivo by immunization with epitope peptide-pulsed syngeneic dendritic cells (DCs) [1].

However, tumor-derived-specific epitope peptides are generally very difficult to determine for most tumors that express either mutated or non-mutated tumor-associated antigens (TAA) containing CTL epitopes. TAA captured by antigen-presenting cells (APCs), such as macrophages or DCs, are generally processed into peptide fragments in acidic endosomes and presented them in conjunction with class II MHC molecules that can stimulate $\mathrm{CD} 4^{+}$helper $\mathrm{T}$ 
lymphocytes (Th), but not $\mathrm{CD} 8^{+}$CTLs restricted by class I MHC [2]. Nevertheless, in some situations, most suitable CTL epitopes within antigenic proteins such as TAA are selected to present in conjunction with class I MHC even when the externally added antigenic proteins are captured by APCs. This phenomenon is called "cross-presentation" $[3,4]$. So far, we have shown that cross-presentation can be induced when antigenic proteins are administered with a specific adjuvant, such as ISCOMs [5] or with TLR3 ligand poly(I:C) [6]. The key cells to generate such cross-presentation are DCs. Recently, it has been demonstrated that two major distinct subsets of DCs are arranged to regulate our immune responses in vivo; 33D $1^{+}$and DEC-205 ${ }^{+}$DCs [7]. More recently, it has been reported that in vivo targeting of DEC-205 with either poly(I:C) [8] or an antibody specific for DC-NK lectin group receptor-1 (DNGR-1) [9] induced dominant Th1 immunity or potent CTL responses via crosspresentation, respectively. Moreover, DCs have been found to directly activate tumor-specific NK cells in the innate arm of the immune system [10]. These results suggest that selective stimulation of DEC- $205^{+}$DCs in vivo may elicit effective acquired $\mathrm{CD} 8^{+} \mathrm{CTL}$ responses through $\mathrm{Th} 1$ dominancy and trigger innate NK cells, by both of which protective immunity against implanted tumors will be achieved even in the absence of externally added tumor antigens.

In the present study, we attempted to deplete $33 \mathrm{D} 1^{+}$ DCs in vivo to establish DEC- $205^{+}$DC dominancy by inoculation with anti-33D1-specific monoclonal antibody $(\mathrm{mAb})$, and DEC- $205^{+} \mathrm{DC}$-dominant mice were successfully obtained in which $33 \mathrm{D} 1^{+} \mathrm{DCs}$ were completely eliminated for at least several weeks. To our surprise, based on our recent findings [11], when 33D $1^{+}$ DC-depleted mice were injected twice with LPS at weekly intervals, $100 \mu \mathrm{g}$ on day 3 and $50 \mu \mathrm{g}$ on day 10 after syngeneic Hepa1-6 hepatoma or B16-F10 melanoma implantation, apparent inhibition of already established tumor growth, probably mediated through IL-12 secretion from the remaining DEC- $205^{+}$DCs, was observed in vivo, although no tumor-derived substances were co-administrated. Moreover, lung metastasis of B16-F10 melanoma in 33D $1^{+}$DC-depleted mice seemed to be suppressed mainly by NK cells that might also be activated by IL-12 secreted via LPS stimulation. Furthermore, intraperitoneal (ip) administration of a small amount of melphalan (L-phenylalanine mustard; L-PAM) $(0.25 \mathrm{mg} / \mathrm{kg})$ in LPS-stimulated 33D1 ${ }^{+}$DC-deleted mice helped to induce $\mathrm{H}-2 \mathrm{~K}^{\mathrm{b}}$-restricted epitope-specific $\mathrm{CD} 8^{+}$ CTLs among tumor-infiltrating lymphocytes (TILs) against already established syngeneic E.G7-OVA lymphoma. These findings suggest that selective stimulation of innate DEC-205 ${ }^{+}$DCs in vivo may assist in generating effective acquired epitope-specific class I MHC molecule-restricted conventional $\mathrm{CD} 8^{+}$CTLs or NK cells against already established tumors without externally added tumor antigen stimulation when they are slightly attacked in vivo with a very small amount of anticancer drugs, such as L-PAM.

\section{Materials and methods}

Mice

Six- to 7-week-old female C57BL/6 $\left(\mathrm{H}-2^{\mathrm{b}}\right)$ mice were purchased from Charles River Japan (Kanagawa, Japan), maintained in micro-isolator cages under specific pathogen-free conditions and fed autoclaved laboratory chow and water. All animal experiments were performed according to the guidelines for the care and use of laboratory animals set by the National Institutes of Health (NIH; MD) and approved by the Review Board of Nippon Medical School (Tokyo, Japan).

\section{Syngeneic tumors}

As for syngeneic tumors, Hepa1-6 (hepatoma, H-2 ${ }^{\mathrm{b}}$ ), B16F10 (melanoma, H-2 ${ }^{b}$ ) and E.G7-OVA (thymoma, H-2 $2^{b}$ ) cells were obtained from American Type Culture Collection (ATCC). B16-OVA (melanoma, H-2 $2^{b}$ ) cells were kindly gifted by Prof. Lieping Chen, Johns Hopkins University School of Medicine.

In vivo depletion of $33 \mathrm{D} 1^{+} \mathrm{DCs}, \mathrm{CD} 8^{+} \mathrm{T}$ cells, or $\mathrm{NK}$ cells

Culture supernatants of 33D1 or 3.155 hybridoma cells (ATCC, VA, USA) were collected and 33D1 mAb against DC inhibitory receptor-2 (DCIR2) or $3.155 \mathrm{mAb}$ (rat IgM) against mouse CD8 was purified from the supernatant by ion-exchange chromatography using diethylaminoethyl (DEAE) cellulose (DE52; Whatman, Maidstone, UK) as previously described [12]. For in vivo depletion of 33D1 ${ }^{+}$ DCs, mice were intraperitoneally (ip) injected with $0.5 \mathrm{mg}$ purified 33D1 mAb or control rat IgG (Jackson Immuno Research Laboratories, PA) for three consecutive days and boosted with $0.5 \mathrm{mg}$ of the same $\mathrm{IgG} 14$ days after the first injection. For in vivo depletion of $\mathrm{CD}^{+} \mathrm{T}$ cells, mice were ip injected with $0.5 \mathrm{mg}$ anti-CD8 $\mathrm{mAb}$ (3.155) or control rat IgM (Rockland, PA) for three consecutive days and boosted with $0.5 \mathrm{mg}$ of the same IgM 14 days after the first injection.

For in vivo depletion of NK cells, mice were intravenously (iv) injected with $20 \mu \mathrm{l}$ anti-asialo GM1 Ab (Wako Pure Chemical Industries, Osaka, Japan) or control rabbit serum diluted to $300 \mu 1$ with PBS for three consecutive days and boosted with the same antiserum once a week. 
Preparation of intraepithelial (IE) cells, spleen (SP) cells, lung cells and TILs, as well as enrichment of DC or lymphocyte population

IE cells, SP cells, lung cells and TILs were prepared by the method described previously [11]. To prepare IE cells, after the small intestine was obtained from a mouse, fecal materials were flushed from the lumen with HBSS (Invitrogen Life Technologies, CA) and connective tissues were carefully removed. The obtained intestine was inverted and cut into several segments that were transferred to a $50 \mathrm{ml}$ conical tube (Becton Dickinson Labware, $\mathrm{NJ}$ ) containing $45 \mathrm{ml}$ HBSS with 5\% FCS, $100 \mathrm{U} / \mathrm{ml}$ penicillin (Invitrogen Life Technologies) and $100 \mu \mathrm{g} / \mathrm{ml}$ streptomycin (Invitrogen Life Technologies). The tube was then shaken at $37^{\circ} \mathrm{C}$ for $45 \mathrm{~min}$ (horizontal position; orbital shaker at $150 \mathrm{rpm}$ ). Harvested cells from the intestinal epithelium were passed through an 80-mm nylon mesh to remove tissue debris. To prepare SP cells, lung cells, and TILs, the spleen, lung, or tumor was aseptically removed and cut into small fragments. The tissue fragments were incubated in $1 \mathrm{mg} / \mathrm{ml}$ collagenase D (Roche, Basel, Switzerland) at $37^{\circ} \mathrm{C}$ for $45 \mathrm{~min}$ and crushed gently. The obtained cells were washed and passed through nylon mesh.

DC populations were enriched from IE cells, SP cells and lung cells as described previously [13, 14] and a lymphocyte fraction including NK cells was also obtained from a cell suspension of lung or tumor by the method described previously [11]. To enrich DCs, the obtained cells were suspended in $10 \mathrm{ml}$ of $30 \%(1.045 \mathrm{~g} / \mathrm{ml})$ Percoll solution (Amersham Biosciences, Uppsala, Sweden) overlaid on $2 \mathrm{ml}$ of $60 \%(1.075 \mathrm{~g} / \mathrm{ml})$ Percoll solution. The solution was centrifuged at $950 \mathrm{~g}$ for $20 \mathrm{~min}$ and DCs were recovered at the interphase between 30 and $60 \%$ Percoll solutions. To collect the fraction including lymphocytes and NK cells, cells from the lung or tumor were suspended in $10 \mathrm{ml}$ of $30 \%$ Percoll solution and centrifuged at $1,800 \mathrm{rpm}$ $(620 \mathrm{~g})$ for $20 \mathrm{~min}$. Cells at the bottom were re-suspended in $10 \mathrm{ml}$ of $40 \%$ Percoll solution overlaid on $2 \mathrm{ml}$ of $70 \%$ Percoll solution. The solution was centrifuged at $1,800 \mathrm{rpm}$ for $20 \mathrm{~min}$ and lymphocytes and NK cells were recovered at the interphase of 40 and $70 \%$ Percoll solutions. The collected cells were suspended in complete T cell medium [15] composed of RPMI 1640 medium (Sigma-Aldrich, St. Louis, MO) supplemented with $2 \mathrm{mM}$ L-glutamine (MP Biomedicals), $1 \mathrm{mM}$ sodium pyruvate (Invitrogen Life Technologies), $0.1 \mathrm{mM}$ nonessential amino acid (Invitrogen Life Technologies), a mixture of vitamins (MP Biomedicals), $1 \mathrm{mM}$ HEPES (Invitrogen Life Technologies), $100 \mathrm{U} / \mathrm{ml}$ penicillin (Invitrogen Life Technologies), $100 \mu \mathrm{g} / \mathrm{ml}$ streptomycin (Invitrogen Life Technologies), $50 \mathrm{mM}$ 2-ME (Sigma-Aldrich) and heat-inactivated $10 \%$ FCS.
In vivo stimulation with either LPS or poly(I:C)

Mice were anaesthetized and subcutaneously (sc) injected with $100 \mu \mathrm{g}$ LPS (Sigma-Aldrich) or poly(I:C) (SigmaAldrich) once for the cytokine assay as described previously [6]. Tumor-bearing mice were anaesthetized and sc injected with $100 \mu \mathrm{g}$ LPS once and then boosted with $50 \mu \mathrm{g}$ LPS 7 days after the first injection of LPS.

Measurement of cytokine production

Peripheral blood was collected from anaesthetized mice using heparinized capillary tubes before and 2, 6 and $8 \mathrm{~h}$ after LPS injection. The blood was centrifuged for $10 \mathrm{~min}$ at $6,000 \mathrm{~g}$, and plasma was collected and frozen at $-80^{\circ} \mathrm{C}$ until assay. IL-12-p40 and IL-10 levels in plasma samples were measured using specific ELISA kits (BioSource International, CA) as described previously [6].

\section{In vivo neutralization of IL-12}

For in vivo neutralization of IL-12, mice were ip injected with $100 \mu \mathrm{g}$ anti-mouse IL-12 Ab (R\&D Systems, MN) or control goat IgG (Jackson Immuno Research Laboratories) just before injection of LPS at 3 and 10 days after tumor implantation.

Flow cytometry analysis

Briefly, $1-5 \times 10^{5}$ cells were pre-incubated with $\mathrm{mAb}$ against the Fc gamma receptor (FcgRII/III; 2.4G2) to block FcR-mediated binding, and then double-stained with FITCconjugated $\mathrm{mAb}$ and $\mathrm{PE}$-conjugated $\mathrm{mAb}$. The following mAbs were purchased from BD Biosciences (San Diego, CA); PE-conjugated 33D1, FITC or PE-conjugated CD11c (N418), FITC-conjugated CD3 (145-2C11), PE-conjugated NK1.1 (PK136), PE-conjugated CD4 (RM4-5) and FITC or PE-conjugated $\mathrm{CD} 8 \alpha(53-6.7)$. FITC-conjugated $\mathrm{CD} 8 \beta$ (CT-CD8 $\beta$ ) and DEC-205 (NLDC-145) were purchased from Caltag Laboratories (Burlingame, CA) and Cedarlane (ON, Canada), respectively. PE-conjugated $\mathrm{H}-2 \mathrm{~K}^{\mathrm{b}} / \mathrm{OVA}$ tetramers-SIINFEKL [16] for the detection of OVA-specific CTLs was purchased from Beckman Coulter (Fullerton, CA). Dead cells were determined using propidium iodide (PI; Sigma-Aldrich) or 7-amino-actinomycin $\mathrm{D}$ viability dye (Beckman Coulter), and stained cells were analyzed with FACScan using the CellQuest program (BD Biosciences).

Measurement of in vivo antitumor effects

For in vivo antitumor experiments, C57BL/6 mice were anesthetized and syngeneic Hepa 1-6 (5 × 10 6 , B16-F10 
$\left(1 \times 10^{6}\right)$, B16-OVA $\left(5 \times 10^{5}\right)$, or E.G7-OVA $\left(5 \times 10^{6}\right)$ tumor cells in $100 \mu$ PBS were injected intracutaneously (ic) into abdominal dermal tissue. For tumor metastasis experiments, B16-F10 cells $\left(1 \times 10^{5}\right)$ in $250 \mu \mathrm{l}$ PBS were injected into the tail vein of C57BL/6 mice. The growing tumors implanted into dermal tissues were followed by measuring the length $(a)$ and width $(b)$ and the tumor volume $(V)$ was calculated according to the formula $V=a b^{2} / 2$, as previously reported $[11,17]$. Mice were anesthetized and killed according to the guidelines for the care and use of laboratory animals when the longer axis of each tumor was over $20 \mathrm{~mm}$ or the calculated volume was over $4,000 \mathrm{~mm}^{3}$. To assess pulmonary metastasis, the lungs were removed from mice 14 days after the injection of B16-F10 cells. Metastasis foci of the lung were counted and lung weight was measured.

\section{Chemotherapy}

A fresh stock solution of $10 \mathrm{mg}$ melphalan (L-PAM) (Wako Pure Chemical Industries, Osaka, Japan) per milliliter was prepared just prior to injection, as previously described [18], and was further diluted with Dulbecco's phosphatebuffered saline, $\mathrm{pH}$ 7.2. As a very low non-affected dose [19], $0.25 \mathrm{mg}$ L-PAM per $\mathrm{kg}$ was administered ip 10 days after implantation of E.G7-OVA to mice.

\section{CTL assay}

Freshly isolated SP cells and TILs were used for the CTL assay and cytolytic activity was measured using a standard ${ }^{51} \mathrm{Cr}$-release assay as previously described [15]. In brief, various numbers of effector cells were incubated with $5 \times 10^{3}{ }^{51} \mathrm{Cr}$-labeled targets for $4 \mathrm{~h}$ at $37^{\circ} \mathrm{C}$ in $200 \mu \mathrm{l}$ RPMI 1640 medium containing $10 \%$ FCS in round-bottom 96-well cell culture plates (BD Biosciences). After incubation, the plates were centrifuged for $10 \mathrm{~min}$ at $330 \mathrm{~g}$, and $100 \mu \mathrm{l}$ cell-free supernatants were collected to measure radioactivity with a Packard AutoGamma 5650 counter (Hewlett-Packard Japan). Maximum release was determined from the supernatant of cells that had been lysed by the addition of $5 \%$ Triton $\mathrm{X}-100$, and spontaneous release was determined from target cells incubated without added effector cells. The percentage of specific lysis was calculated as 100 (experimental release - spontaneous release)/(maximum release spontaneous release).

\section{Statistical analysis}

Student's $t$ test was used to determine the statistical significance of differences between groups. Data were considered significant at $P<0.05$.

\section{Results}

Distribution of 33D1- or DEC-205 ${ }^{+}$DCs in the spleen and IE of normal C57BL/6 mice

Based on recent findings [7] that there are two major distinct subsets of DCs controlling antigen presentation in vivo, we first attempted to determine the tissue distribution of 33D1- or DEC-205+ DCs in both systemic lymphoid organs, such as the spleen, and local surface tissues, such as IE of the small intestine, in normal C57BL/6 mice. DCs are usually identified as $\mathrm{CD} 11 \mathrm{c}^{+}$cells by flow cytometry analysis. Among CD $11 \mathrm{c}^{+}$cells, nearly an equal number of 33D $1^{+}$ DCs $(6.1 \%)$ and DEC-205 ${ }^{+}$DCs $(8.4 \%)$ were observed in the spleen, while a lower percentage of DEC-205 ${ }^{+}$cells $(1.2 \%)$ in comparison with $33 \mathrm{D} 1^{+}$DCs $(5.2 \%)$ could be seen among intraepithelial cells (IECs) (Fig. 1a, upper panels). It is important to note that, similar to a recent report by Dudziak et al. [7], CD11 ${ }^{+}$DCs expressing both 33D1 and DEC-205 molecules could not be detected. The results suggest that $33 \mathrm{D}^{+} \mathrm{DCs}$ are equally distributed in both systemic and local tissues, whereas DEC- $205^{+}$DCs are predominantly arranged in systemic compartments rather than local intraepithelia. Many malignant carcinomas originate from various epithelial tissues, where $33 \mathrm{D} 1^{+} \mathrm{DCs}$ are dominantly arranged; therefore, $33 \mathrm{D} 1^{+} \mathrm{DCs}$ in surface epithelial compartments must be involved in local immunological surveillance to achieve antitumor immunity. Thus, we attempted to examine the effect of depletion of the 33D $1^{+}$ DC subset in vivo on challenged tumor growth based on a recently established procedure [11].

In vivo depletion of $33 \mathrm{D} 1^{+} \mathrm{DCs}$ by ip injection of anti-33D1 mAb

We then tried to deplete the 33D $1^{+} \mathrm{DC}$ subset in vivo by ip injection of anti-33D1 mAb in mice. When anti-33D1 Ab (0.5 mg per day) was injected ip for three consecutive days, $33 \mathrm{D} 1{ }^{+} \mathrm{CD} 11 \mathrm{c}^{+}$DCs were successfully depleted in both spleen cells and IECs 1 day after the final inoculation, while no change in the number of DEC-205 ${ }^{+}$DCs was observed in both the spleen and IE (Fig. 1a, lower panels).

To determine the continuation of the effect mediated by the injection of anti-33D1 mAb, we measured the number of $33 \mathrm{D} 1^{+} \mathrm{CD} 11 \mathrm{c}^{+} \mathrm{DCs}$ weekly for three successive weeks. Although $33 \mathrm{D} 1^{+} \mathrm{CD} 11 \mathrm{c}^{+}$DCs were completely deleted until 2 weeks after the injection of anti-33D1 mAb, they recovered at 3 weeks in both spleen cells (1.7\%) and IECs (4.6\%) (Fig. 1b). Accordingly, the mice were boosted once by an additional ip injection of anti-33D $1 \mathrm{mAb}(0.5 \mathrm{mg}$ per day) 2 weeks after the initial injection; 1 and 2 weeks after this boost, 33D1 ${ }^{+}$DCs had completely disappeared in both the spleen and intra-epithelia (Fig. 1b), indicating that 


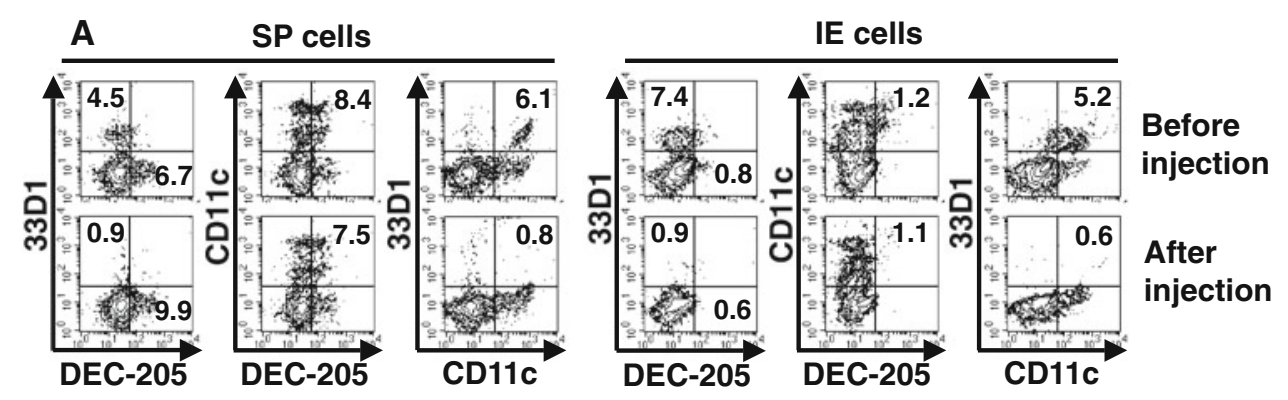

B Before Weeks after the primary injection Weeks after boosting

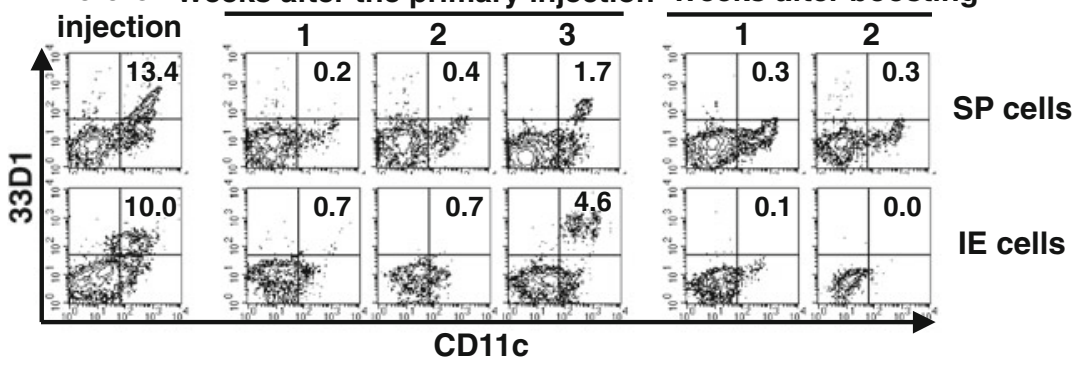

Fig. 1 a Distribution of 33D1- or DEC-205 ${ }^{+}$DCs in the spleen as well as in the intestinal epithelium of normal and anti-33D1 mAb injected C57BL/6 mice. To determine the distribution of 33D1- or DEC-205 ${ }^{+}$ DCs, normal C57BL/6 mice were killed and analyzed by flow cytometry. Distributions of the indicated DC-subtypes either in the spleen (SP) (left six panels) or in the intestinal epithelium (IE) (right six panels) are shown. Among these panels, the upper six panels were obtained from untreated and the lower six panels were from anti-33D1 $\mathrm{mAb}$ ip injected C57BL/6 mice. b Kinetics for in vivo depletion of

successful eradication of the $33 \mathrm{D} 1^{+} \mathrm{DC}$ subset is achievable until at least 4 weeks after the initial inoculation of anti-33D1 mAb using the prime-boost procedure indicated above. In contrast, when the control rat IgG in the same isotype as 33D1 was ip injected into mice, the number of both $33 \mathrm{D}^{+}$and DEC- $205^{+}$DCs remained unchanged (data not shown).

Significant enhancement of IL-12 secretion in $33 \mathrm{D} 1^{+} \mathrm{DC}$-depleted mice

We established 33D1 ${ }^{+}$DC-deficient mice, in which DEC$205^{+}$DCs are predominantly distributed. A recent report indicated that such DEC-205 ${ }^{+}$DCs induced a large number of Th1 type $\mathrm{CD}^{+}{ }^{+} \mathrm{T}$ cells through Toll-like receptor (TLR) signaling if DEC-205 ${ }^{+}$DCs were stimulated by poly(I:C) [8]. Thus, we examined the ability to produce cytokines in the sera of $33 \mathrm{D} 1^{+} \mathrm{DC}$-depleted mice when they were stimulated by a TLR ligand, such as LPS for TLR4 or poly(I:C) for TLR3 based on the procedure described previously [6] since most of the remaining CD $11 \mathrm{c}^{+}$DCs were CD80- and CD86-negative immature DCs (data not shown). Serum IL12 production, which may shift the Th1/Th2 balance into the Th1 predominant state, was significantly enhanced in $33 \mathrm{D}^{+}$DC-depleted mice $(P<0.05) 2,6$ and $8 \mathrm{~h}$ after
$33 \mathrm{D} 1^{+} \mathrm{DCs}$ by ip injection of anti-33D1 mAb. To determine the continuation of the effect by anti-33D1 mAb treatment, C57BL/6 mice were killed and the percentage of remaining $33 \mathrm{D} 1^{+} \mathrm{DCs}$ either in the SP (upper six panels) or in the IE (lower six panels) was measured by flow cytometry every week for three successive weeks after anti-33D1 $\mathrm{mAb}$ ip injection. To achieve complete elimination of $33 \mathrm{D} 1^{+} \mathrm{DCs}$, single additional ip injection of anti-33D1 mAb was performed 2 weeks after the initial administration, and their effect was examined for at least another 2 weeks (right four panels)

single sc injection with $100 \mu \mathrm{g}$ LPS, the ligand for TLR4, when compared with control mice treated with rat $\mathrm{IgG}$, whereas an injection of $100 \mu \mathrm{g}$ poly(I:C), the ligand for TLR3, showed weaker secretion of IL-12 than LPS stimulation in our $33 \mathrm{D} 1^{+}$DC-depleted mice (Fig. 2). In addition, serum IL-10 production was almost identical to stimulation with LPS between 33D1 $1^{+}$DC-depleted mice and control untreated mice, but serum IL-10 could not be detected when poly(I:C) was injected into those mice (Fig. 2). These results indicate that in vivo depletion of $33 \mathrm{D} 1^{+} \mathrm{DCs}$ can cause significant enhancement of IL-12, but not IL-10 production by stimulation with LPS, which may induce Th1 dominancy upon TLR signaling.

Suppression of implanted tumor growth at the dermis in $33 \mathrm{D} 1^{+} \mathrm{DC}$-depleted mice with LPS stimulation

To examine the in vivo effects of Th1 dominancy on antitumor immunity, 33D1 ${ }^{+}$DC-depleted C57BL/6 mice, in which such Th1 dominancy can be achieved via LPS stimulation, each mouse was implanted with a $5 \times 10^{6}$ syngeneic Hepa1-6 hepatoma cell line into the dermis and simultaneously injected sc once with $100 \mu \mathrm{g}$ LPS. The growth of implanted Hepa1-6 was significantly suppressed when compared with control rat IgG-treated mice, although there 

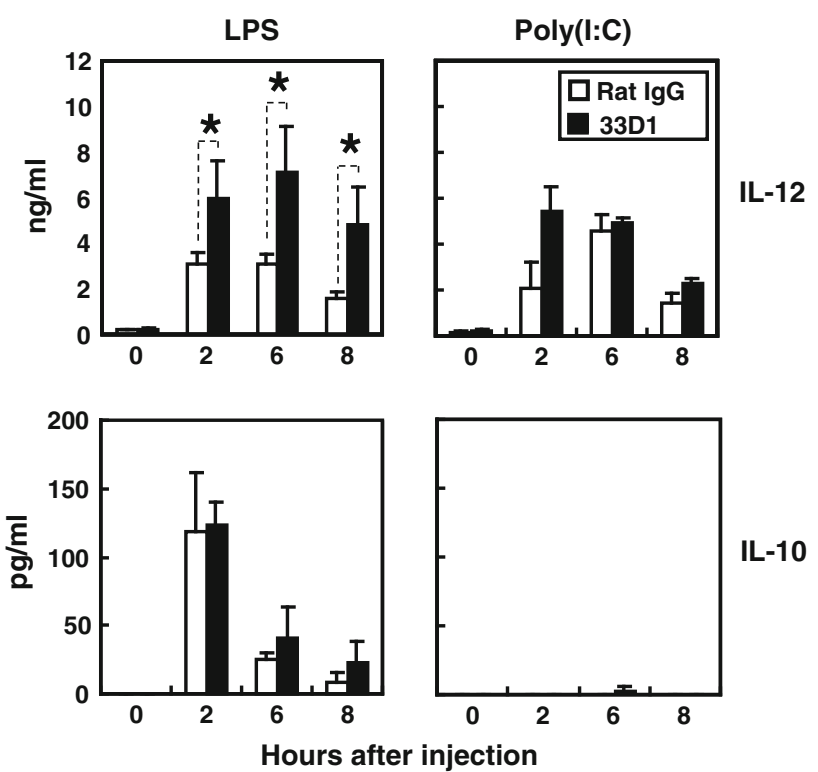

Fig. 2 Significant enhancement of IL-12 secretion in 33D1 $1^{+}$DC-depleted mice. To examine the ability to secrete cytokines in the sera of $33 \mathrm{D} 1^{+} \mathrm{DC}$-depleted mice (filled bars), they were sc administrated once either with $100 \mu \mathrm{g}$ LPS, the ligand for TLR4, or with $100 \mu \mathrm{g}$ poly(I:C), the ligand for TLR 3 and the amount of two representative cytokines, IL-10 and IL-12, was measured by ELISA at 2, 6 and $8 \mathrm{~h}$ after stimulation. Upper panels show the amounts of IL-12 and lower panels IL-10 after single sc injection of LPS (left two panels) or poly(I:C) (right two panels). Open bars indicate the sera from control mice injected with isotype-matched $\mathrm{mAb}(\mathrm{rat} \mathrm{IgG})$. Asterisk $(*)$ indicates statistically significant differences $(P<0.05)$ between $33 \mathrm{D} 1^{+} \mathrm{DC}$ depleted and control rat-IgG-treated groups

was no difference between groups without LPS stimulation (Fig. 3a).

Moreover, based on our recent findings [11], when 33D $1^{+}$DC-depleted mice were injected sc twice with LPS at weekly intervals, $100 \mu \mathrm{g}$ on day 3 and $50 \mu \mathrm{g}$ on day 10 after syngeneic tumor implantation, apparent inhibition of already established B16-F10 growth in vivo was observed (Fig. 3b), which may have been caused by tumor-infiltrating $\mathrm{CD}^{+} \mathrm{T}$ lymphocytes seen in tissue specimens (data not shown).

To determine whether secreted IL-12 is critical for tumor regression in $33 \mathrm{D} 1^{+} \mathrm{DC}$-depleted mice, $100 \mu \mathrm{g}$ anti-mouse IL-12 Ab or control goat IgG was ip injected just after LPS stimulation on day 3 and 10 days after B16-F10 tumor implantation. When mice were treated with control goat $\mathrm{IgG}$, tumor growth was still significantly suppressed (Fig. 3c; upper panel), in which serum IL-12 secretion at 2 and $6 \mathrm{~h}$ after LPS stimulation was enhanced when compared with mice treated with control rat IgG (Fig. 3d; upper panel). In contrast, tumor growth suppression in $33 \mathrm{D} 1^{+}$ DC-depleted mice was totally abrogated (Fig. 3c; lower panel) when serum IL-12 was neutralized by an injection of anti-mouse IL-12 Ab just before LPS stimulation (Fig. 3d; lower panel).
Furthermore, to confirm whether $\mathrm{CD} 8^{+} \mathrm{T}$ cells are critical in the suppression of implanted tumor growth in 33D $1^{+}$ DC-depleted mice, $\mathrm{CD} 8^{+} \mathrm{T}$ cells were depleted in vivo and tumor growth of B16-F10 was pursued (Fig. 3e, f). As indicated in Fig. 3e (lower panel), suppression of tumor growth was abrogated in 33D1 $1^{+}$DC-depleted mice when $\mathrm{CD} 8^{+} \mathrm{T}$ cells were depleted in vivo by injection of anti-mouse CD8 $\mathrm{mAb}$ (3.155) (Fig. 3f). These results suggest that in vivo production of IL-12 in 33D $1^{+}$DC-depleted mice via LPS stimulation might be required to suppress tumor growth in the dermis by tumor-infiltrating $\mathrm{CD} 8^{+} \mathrm{T}$ cells.

Suppression of lung metastasis of B16-F10 melanoma in 33D $1^{+}$DC-depleted mice stimulated with LPS

As shown in Fig. 3b, we observed marked suppression of B16-F10 melanoma growth implanted into the dermis. Thus, we attempted to determine whether the development of B16-F10 lung metastasis could be suppressed in 33D1 ${ }^{+}$ DC-depleted mice when stimulated with LPS. 33D $1^{+}$DCdepleted C57BL/6 mice were injected intravenously (iv) with $1 \times 10^{5}$ B16-F10 melanoma suspended with $0.25 \mathrm{ml}$ PBS $(-)$ via the tail vein per mouse and then stimulated twice with LPS at weekly intervals, $100 \mu \mathrm{g}$ at day 3 and $50 \mu \mathrm{g}$ at day 10 after syngeneic tumor implantation. Fourteen days after the injection of B16-F10 melanoma, the number of lung metastases in each mouse was counted. The number of lung metastasis in $33 \mathrm{D}^{+}{ }^{+} \mathrm{DC}$-depleted, LPStreated mice was apparently reduced in comparison with control mice treated with rat IgG or LPS alone visually (Fig. 4a) as well as numerically (Fig. 4b). This was confirmed by significant reduction in the total volume of the lung in $33 \mathrm{D} 1^{+}$DC-depleted, LPS-treated mice $(P<0.01$; Fig. $4 \mathrm{c})$. These results clearly demonstrate that not only growth of the tumor implanted into the dermis, but also the development of lung metastasis could be suppressed in 33D $1^{+}$DC-depleted mice when they were stimulated with LPS.

Suppression of lung metastasis of B16-F10 melanoma cells by NK cells

To determine the cells involved in the suppression of lung metastasis by LPS stimulation in $33 \mathrm{D} 1^{+} \mathrm{DC}$-depleted mice, lymphocyte subsets obtained from lung tissues with B16F10 melanoma metastasis were analyzed by flow cytometry. Importantly, the percentage of $\mathrm{NK} 1.1^{+} \mathrm{CD}^{-} \mathrm{NK}$ cells in the lung tissues of LPS-stimulated $33 \mathrm{D} 1^{+} \mathrm{DC}$-deleted mice, in which metastasis development was apparently suppressed, were markedly increased when compared with the untreated control $(P=0.058)$ or isotype-matched ratIgG-treated mice (Fig. 5a, b). In addition, there was no difference in the percentage of $\mathrm{CD} 8^{+} \mathrm{T}$ cells in lung tissues 

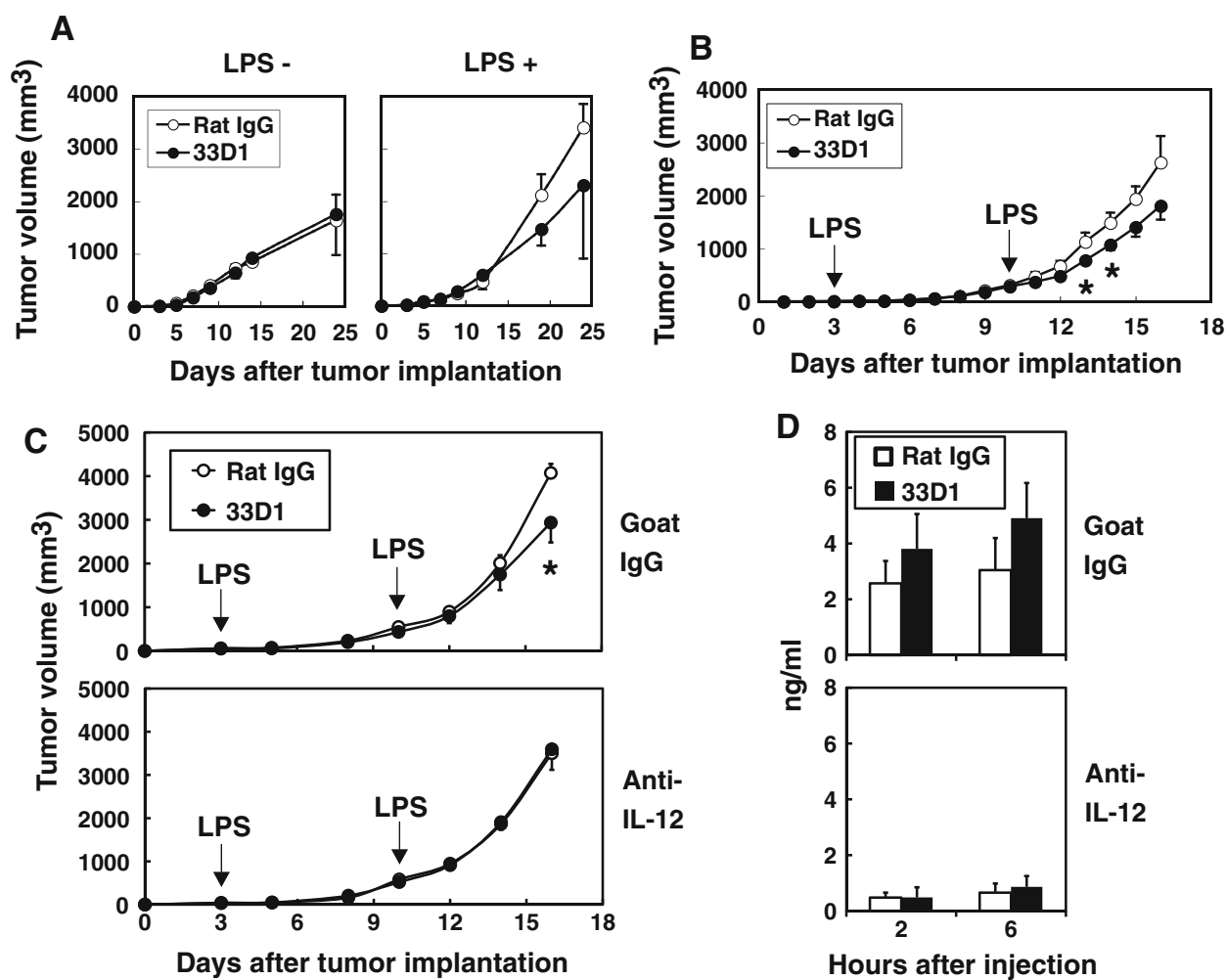

Hours after injection

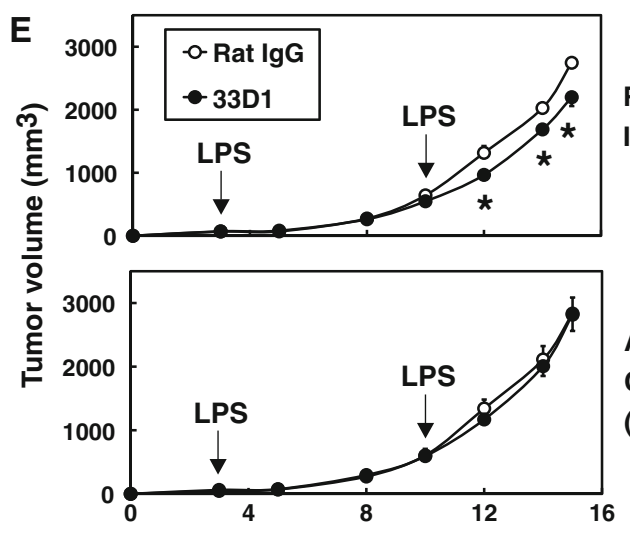

Days after tumor implantation

Rat IgM

Anti-

CD8

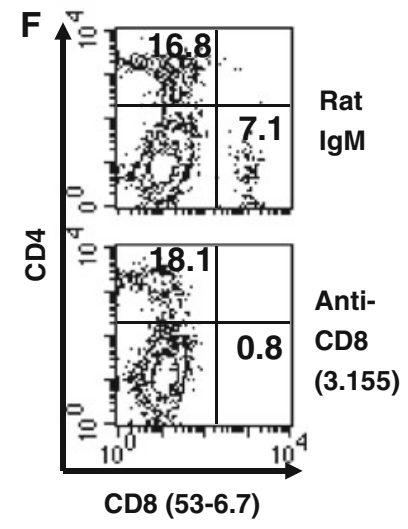

Fig. 3 Suppression of tumor growth implanted into the dermis of $33 \mathrm{D} 1^{+}$DC-depleted mice with LPS stimulation and effect of blocking on IL-12 secretion and depletion of $\mathrm{CD}^{+} \mathrm{T}$ cells for suppression. a $5 \times 10^{6}$ syngeneic Hepa1-6 hepatoma cells were injected into the dermis of $33 \mathrm{D} 1^{+} \mathrm{DC}$-depleted (filled circle) or control isotype-matched rat-IgG-treated (open circle) C57BL/6 mice. Based on the findings in Fig. 2, $100 \mu \mathrm{g}$ LPS was injected sc together with the implantation of Hepa1-6 cells (right panel). b, c, e $1 \times 10^{6}$ syngeneic B16-F10 melanoma cells were injected into the dermis of $33 \mathrm{D} 1^{+} \mathrm{DC}$-depleted (closed circle) or control rat-IgG-treated (open circle) C57BL/6 mice, which were injected twice with LPS at weekly intervals, $100 \mu \mathrm{g}$ on day 3 and $50 \mu \mathrm{g}$ on day 10 after tumor implantation. Asterisk $(*)$ indicates statis-

tically significant differences $(P<0.05)$ between $33 \mathrm{D} 1^{+}$DC-depleted and control rat-IgG-treated groups on the same day. Mice were also treated with anti-mouse IL-12-specific Ab or control goat IgG just before LPS injection on day 3 and 10 for in vivo neutralization of IL-12 (c) or anti-mouse CD8 Ab (3.155) or control rat IgM at days 7, 6 and 5 before and day 7 after tumor injection for in vivo depletion of $\mathrm{CD}^{+} \mathrm{T}$ cells $(\mathbf{e})$. d Sera were collected from $33 \mathrm{D}^{+}{ }^{+}$DC-depleted (filled bars) or control mice (open bars) 2 and $6 \mathrm{~h}$ after LPS stimulation following ip injection with anti-mouse IL-12 Ab or goat $\mathrm{IgG}$, and IL-12 p40 in the sera was measured by ELISA. $\mathrm{CD} 4^{+}$and $\mathrm{CD} 8^{+} \mathrm{lym}-$ phocytes in the spleen from mice 7 days after injection with anti-CD8 $\mathrm{Ab}$ or rat $\mathrm{IgM}$ were analyzed by flow cytometry

bearing metastasis between rat-IgG-treated and 33D1treated mice (Fig. 5b).

To confirm whether NK cells are important in the suppression of B16-F10 tumor metastasis, NK cells were

depleted in vivo by anti-asialo GM1 Ab treatment. Mice were iv injected with anti-asialo GM1 Ab for NK cell depletion or control rabbit serum and ip injected with 33D1 $\mathrm{mAb}$ or control rat IgG before iv injection of B16-F10 


\section{A \\ Untreated LPS S.c. B16 iv. LPS s.c. LPS s.c.}

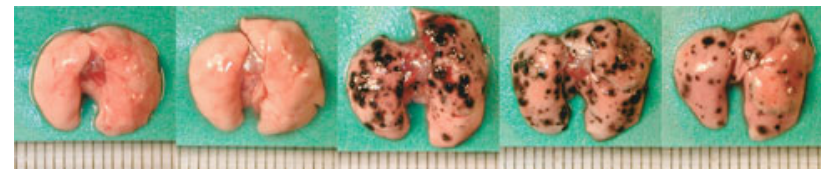

B
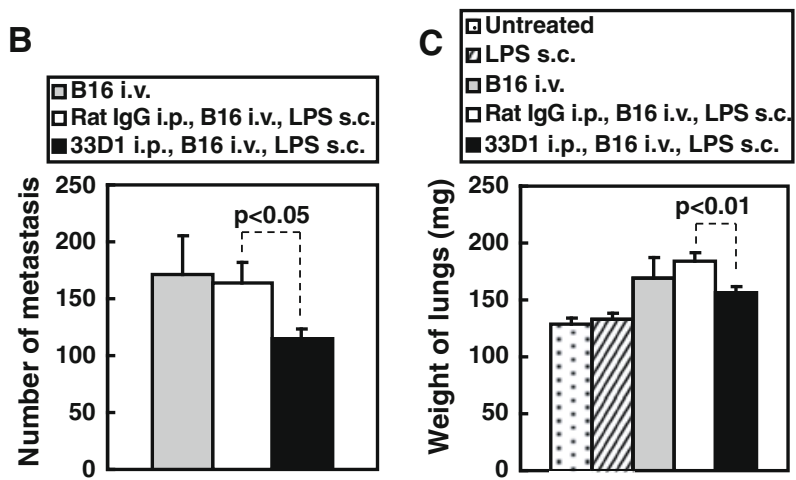

Fig. 4 Suppression of lung metastasis of B16-F10 melanoma in $33 \mathrm{D} 1^{+}$DC-depleted mice stimulated with LPS. 33D $1^{+}$DC-depleted C57BL/6 mice were injected iv with $1 \times 10^{5} \mathrm{~B} 16-\mathrm{F} 10$ melanoma cells via the tail vein per mouse and then stimulated twice with LPS at weekly intervals, $100 \mu \mathrm{g}$ on day 3 and $50 \mu \mathrm{g}$ on day 10 after syngeneic tumor injection. Fourteen days after iv injection of B16-F10 melanoma, the number of lung metastases in each mouse was counted either visually (a) or numerically (b). Total volume of the lung in $33 \mathrm{D} 1^{+}$DC-depleted, LPS-treated mice was significantly reduced $(P<0.01)(\mathbf{c})$

melanoma, and then stimulated with LPS as described above. To our surprise, B16-F10 metastasis in the lungs of NK cell-depleted mice seriously progressed visually (Fig. 5c) and the weight of their lungs markedly increased (Fig. 5d) regardless of 33D $1^{+} \mathrm{DC}$ depletion when compared with metastasis in control mice without NK cell depletion. In the lung of 33D $1^{+} \mathrm{DC}$-depleted mice treated with control rabbit serum, in which B16-F10 metastasis was apparently suppressed (Fig. 5c, d), the percentage of NK1.1 $1^{+} \mathrm{CD}^{-} \mathrm{NK}$ cells (Fig. 5e) and their NK activity against YAC-1 target cells (Fig. 5f) were markedly enhanced. In addition, it should be noted that some NK1.1 $1^{+} \mathrm{CD}^{+}$NKT cells were observed in the metastatic lung (Fig. 5e), although the actual function of those NKT cells remains to be elucidated.

Thus, lung metastasis seems to be suppressed by NK cells that might be activated also via IL-12. Collectively, in $33 \mathrm{D}^{+}{ }^{+}$DC-deleted mice, upon stimulation with LPS, the remaining DEC- $205^{+}$DCs may secrete IL-12, by which tumor-specific $\mathrm{CD} 8^{+} \mathrm{CTLs}$ and NK cells are activated without co-administration of tumor antigens, and the former activated CTLs seems to inhibit the implanted tumor growth and the latter activated NK cells may suppress tumor metastasis.
Induction of $\mathrm{H}-2 \mathrm{~K}^{\mathrm{b}}$-restricted epitope-specific $\mathrm{CD} 8^{+} \mathrm{CTLs}$ among TILs in 33D $1^{+}$DC-depleted mice stimulated with LPS

To determine whether the cells involved in tumor regression are class I MHC molecule-restricted epitope-specific conventional $\mathrm{CD}^{+}$CTLs in this system, we conducted similar experiments using syngeneic B16-OVA melanoma cells expressing the known CTL epitope (SIINFEKL) presented by $\mathrm{K}^{\mathrm{b}}$ class I MHC molecules. Control mice or 33D $1^{+}$DC-deleted mice were sc implanted with B16-OVA melanoma and ip injected with LPS twice as described above. The growth of implanted B16-OVA melanoma $33 \mathrm{D} 1^{+}$DC-depleted mice was significantly $(P<0.05)$ suppressed in comparison with control rat-IgG-treated mice (Fig. 6a). It should be noted that $\mathrm{H}-\mathrm{K}^{\mathrm{b}} / \mathrm{OVA}$ tetramer-positive cells apparently increased among freshly isolated $\mathrm{CD} 8^{+}$ TILs from 33D $1^{+}$DC-deleted mice, although tetramer-positive cells were not seen in the spleens of the same mice (Fig. 6b; left panel). In addition, the percentage of NK1. $1^{+} \mathrm{CD}^{-} \mathrm{NK}$ cells as well as NK1.1 $1^{+} \mathrm{CD}^{+} \mathrm{NKT}$ cells was increased in TILs from $33 \mathrm{D} 1^{+}$DC-deleted mice (Fig. 6b; right panel).

These results suggest that selective stimulation of innate DEC- $205^{+}$DCs by $33 \mathrm{D} 1^{+}$DC depletion and LPS injection might effectively induce not only tumor antigen-specific $\mathrm{CD}^{+} \mathrm{T}$ cells, but also NK and NKT cells in tumor tissues, which suppress tumor growth in the dermis.

IP co-administration of a very low dose of L-PAM with LPS helped to induce $\mathrm{H}-2 \mathrm{~K}^{\mathrm{b}}$-restricted epitope-specific $\mathrm{CD} 8^{+}$CTLs among TILs against E.G7-OVA tumor

The previous findings obtained using B16-OVA (Fig. 6a, b) suggest that selective stimulation of innate DEC- $205^{+}$DCs in vivo may assist to generate effective acquired epitopespecific class I MHC molecule-restricted conventional $\mathrm{CD} 8^{+}$CTLs against already established tumors without externally added tumor antigen stimulation. To confirm this observation, we used another syngeneic tumor cells, E.G7OVA thymoma, expressing the same CTL epitope (SIINFEKL) presented by $\mathrm{K}^{\mathrm{b}}$ class I MHC molecules as B16-OVA.

In comparison with other syngenic tumors, such as Hepa1-6, B16-F10 and B16-OVA, the regression of implanted E.G7-OVA in $33 \mathrm{D} 1^{+}$DC-deleted mice was almost unchanged by two injections of LPS. Nevertheless, ip inoculation of L-PAM at a very low dose $(0.25 \mathrm{mg} / \mathrm{kg})$ 10 days after implanting E.G7-OVA in a mouse resulted in marked reduction in the implanted EG7-OVA (Fig. 6c; $P<0.05$ ). It should be noted that $\mathrm{H}-2 \mathrm{~K}^{\mathrm{b}} / \mathrm{OVA}$ tetramerpositive cells apparently increased among freshly isolated 
A Untreated Rat lgG i.p. 33D1 i.p.

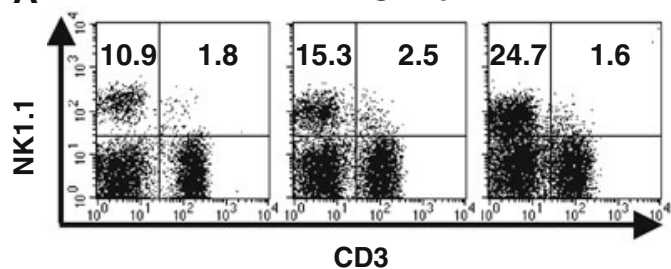

B

\begin{tabular}{lcccc}
\hline & NK1.1+ CD3- & NK1.1+CD3+ & CD8 $\alpha \alpha+$ & CD8 $\alpha \beta+$ \\
\hline Untreated & $9.3 \pm 2.1$ & $0.7 \pm 0.1$ & $0.5 \pm 0.0$ & $14.9 \pm 1.5$ \\
Rat IgG i.p. & $11.5 \pm 2.1$ & $1.1 \pm 0.3$ & $2.7 \pm 0.9$ & $22.1 \pm 4.3$ \\
33D1 i.p. & $16.8 \pm 1.9 *$ & $1.0 \pm 0.2$ & $2.3 \pm 0.3$ & $17.8 \pm 1.0$
\end{tabular}
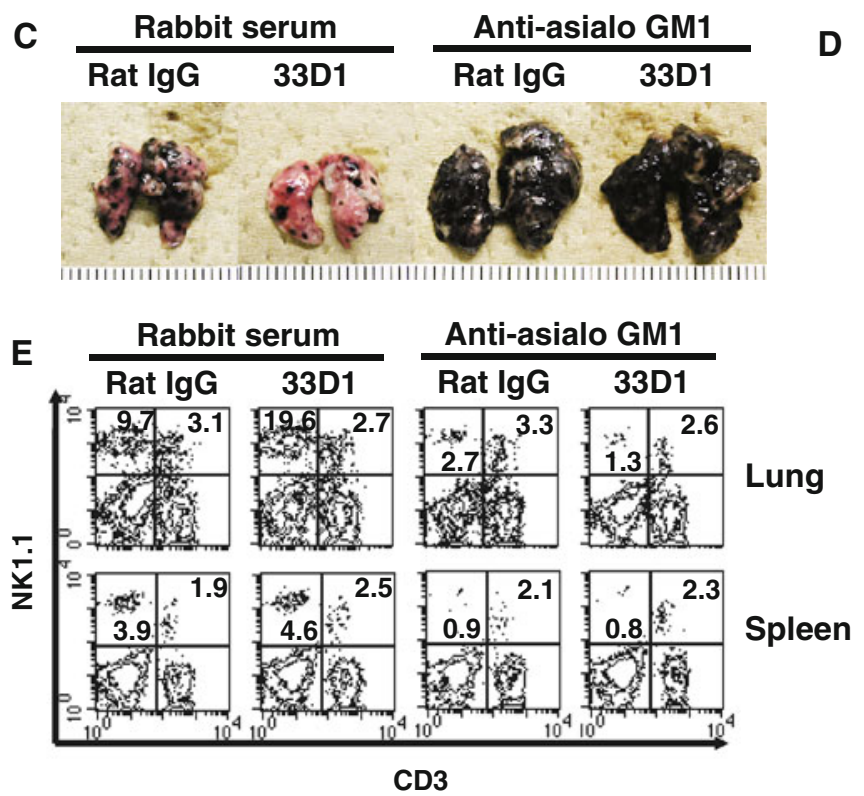

D Rabbit serum, rat IgG

- Rabbit serum, 33D1

Anti-asialo GM1, rat lgG

$\square$ Anti-asialo GM1, 33D1

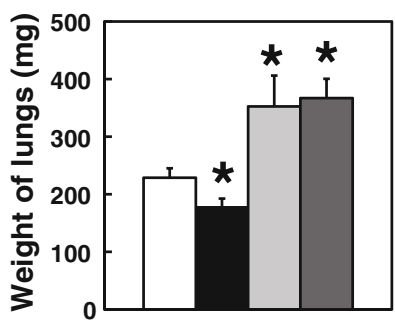

$\mathbf{F}$
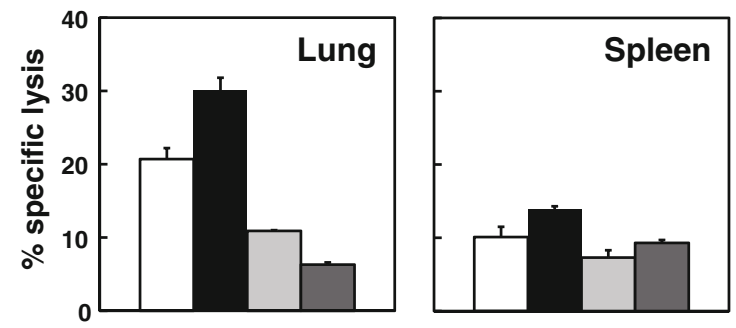

Fig. 5 Effect of number of NK cells on lung metastasis development. a, $\mathbf{b}$ To determine the cells involved in the suppression of tumor metastasis, lymphocyte subsets obtained from lung tissues with B16-F10 metastasis were analyzed by flow cytometry. The percentage of $\mathrm{NK} 1.1^{+} \mathrm{CD}^{-} \mathrm{NK}$ cells in the lung tissues of untreated mice and LPSstimulated $33 \mathrm{D} 1^{+} \mathrm{DC}$-deleted mice was determined by flow cytometry analysis (a). The results are shown as the mean of the percentage \pm SEM from 3 to 4 mice (b). Asterisk $(*)$ indicates statistical differences $(P=0.058)$ between the $33 \mathrm{D} 1^{+} \mathrm{DC}$-depleted group and untreated group. c-f Effect of depletion of NK cells in vivo by anti-asialo GM1specific Ab. NK cell-depleted mice were injected iv with $1 \times 10^{5} \mathrm{~B} 16-$ F10 melanoma cells and stimulated twice with LPS at weekly intervals,
$100 \mu \mathrm{g}$ on day 3 and $50 \mu \mathrm{g}$ on day 10 after tumor injection. Fourteen days after iv injection of B16-F10 melanoma, lung (c) and SP were removed from the mice and the weight of each lung was measured (d). Asterisk (*) indicates statistically significant differences $(P<0.05)$ between the control group treated with both rabbit serum with rat IgG and each treated group. Percentages of NK $1.1^{+} \mathrm{CD}^{-}$cells $(\mathbf{e})$ and NK activity (f) in the lung and SP cells were analyzed by flow cytometry and ${ }^{51} \mathrm{Cr}$-release assay using YAC-1 cells as targets. The results are shown as the mean \pm SEM of triplicates from pooled lung or SP cells obtained from 3 to 4 mice. The effector: target (E:T) ratio is 100:1 or 80:1 in spleen or lung cells, respectively (f) 


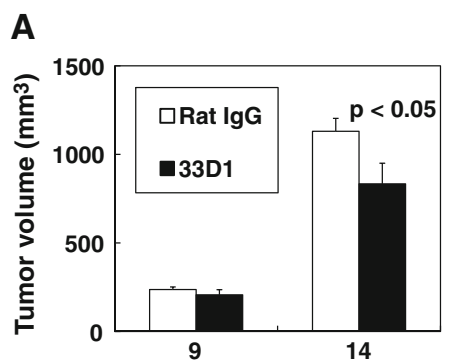

Days after tumor implantation
B

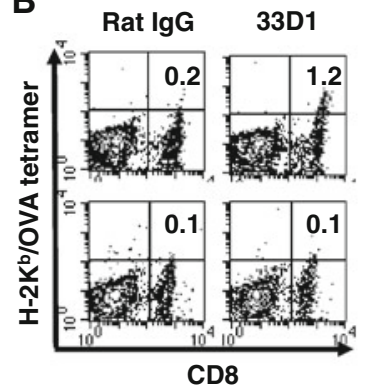

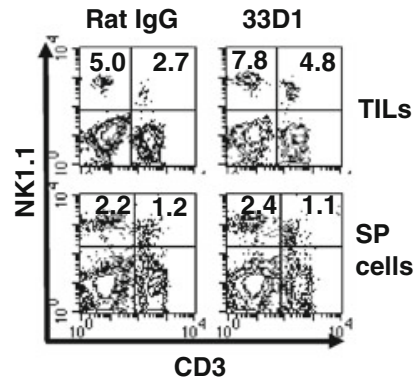

CD3
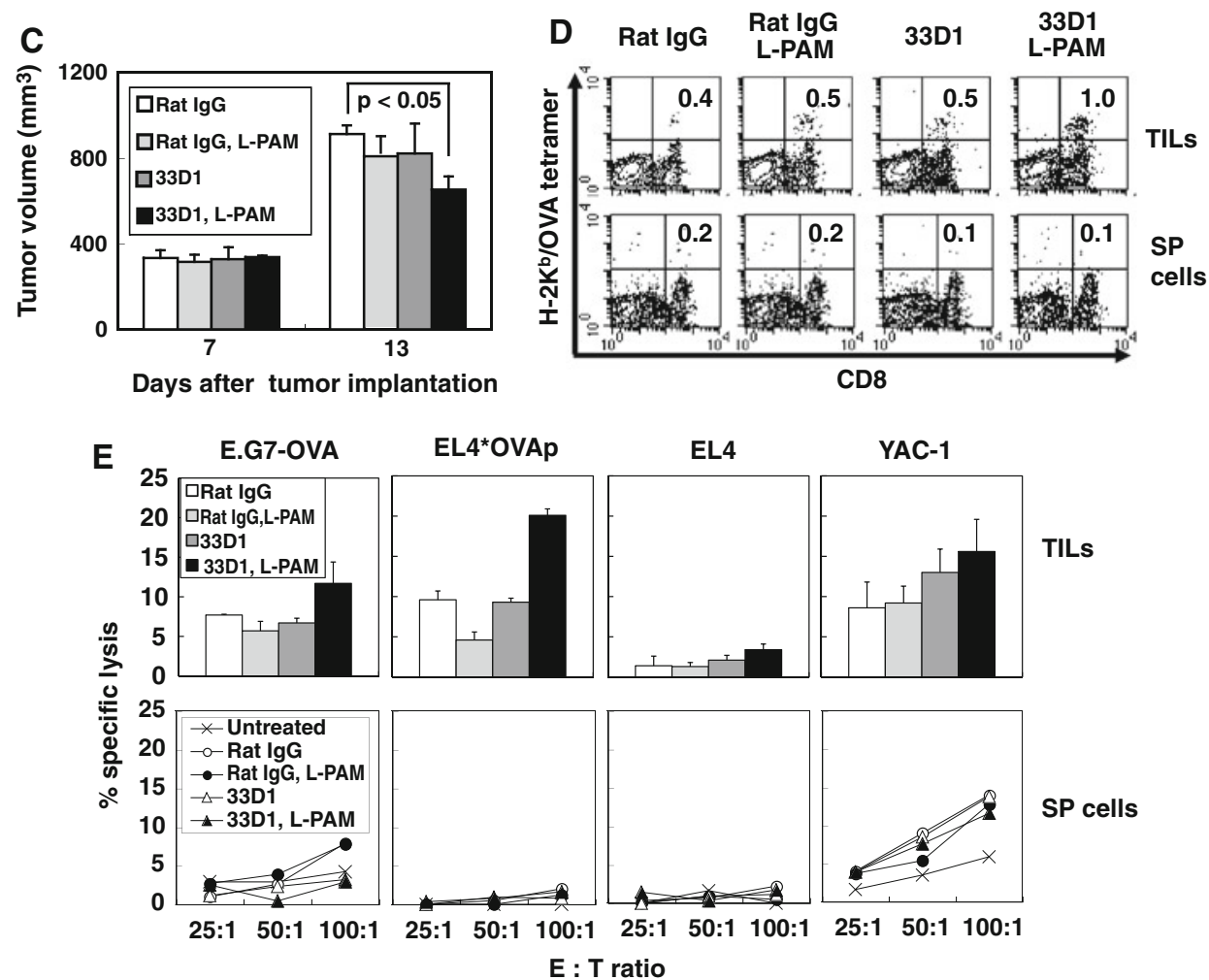

Fig. 6 Suppression of B16-OVA tumor growth implanted into the dermis and infiltration of OVA-specific CTLs into the tumor in $33 \mathrm{D} 1^{+}$ DC-depleted mice. $5 \times 10^{5}$ syngeneic B16-OVA melanoma cells were injected into the dermis of $33 \mathrm{D} 1^{+} \mathrm{DC}$-depleted or control isotypematched rat-IgG-treated C57BL/6 mice, which were injected twice with LPS at weekly intervals, $100 \mu \mathrm{g}$ on day 3 and $50 \mu \mathrm{g}$ on day 10 after tumor implantation. Tumor growth $(\mathbf{a})$ of $33 \mathrm{D} 1^{+}$DC-depleted mice was significantly suppressed $(P<0.05)$ on day 14 after tumor implantation, compared with mice treated with control rat IgG. To determine the cells involved in the suppression of B16-OVA melanoma implanted into the dermis, lymphocyte subsets were obtained from SP and tumor on day 14. These SP cells and TILs were stained with PE-labeled H-2 K $/ \mathrm{OVA}$ tetramer and FITC-labeled anti-CD8 or PE-labeled anti-NK1.1 and FITC-labeled anti-CD3, and analyzed by flow cytometry (b). c, d, e Effect of additional L-PAM (non-toxic dose) injection on the enhancement of epitope-specific CTL induction. $5 \times 10^{6}$ syngeneic E.G7-OVA thymoma cells were injected into the

$\mathrm{CD}^{+}$TILs from $33 \mathrm{D} 1^{+}$DC-deleted mice treated with L-PAM, although the tetramer-positive cells were not seen in the spleen of the same mice (Fig. 6d). Moreover, freshly isolated such tetramer-positive $\mathrm{CD}^{+}$lymphocytes showed dermis of $33 \mathrm{D}^{+}$DC-depleted or control isotype-matched rat-IgGtreated C57BL/6 mice, which were injected twice with LPS at weekly intervals, $100 \mu \mathrm{g}$ on day 3 and $50 \mu \mathrm{g}$ on day 10 after tumor implantation. L-PAM $(0.25 \mathrm{mg} / \mathrm{kg})$ was ip injected some of these mice at day 10 after the tumor implantation. Tumor growth (c) of mice treated with both 33D1 and L-PAM was significantly suppressed $(P<0.05)$ on day 13 after tumor implantation ( 3 days after L-PAM treatment), compared with mice treated with control rat IgG. To determine cells involved in the suppression of E.G7-OVA tumor implanted into the dermis, lymphocyte subsets were obtained from SP and tumor on day 13. These SP cells and TILs were stained with PE-labeled $\mathrm{H}-2 \mathrm{~K}^{\mathrm{b}} / \mathrm{OVA}$ tetramer and FITC-labeled anti-CD8 and analyzed by flow cytometry (d). OVAspecific CTL and NK activity of SP cells and TILs were measured by a ${ }^{51}$ Cr-release assay using E.G7-OVA, YAC-1 and EL4 cells pulsed with or without OVA peptide as targets (e). The E:T ratio was $36: 1$ in TILs or 100:1, 50:1 and 25:1 in SP cells

marked epitope-specific cytotoxic activities (Fig. 6e), while slight epitope-specific cytotoxic activities were observed in other controls (Fig. 6e). This may be caused by two sc injections with LPS because no cytotoxicity could be 
detected in freshly isolated TILs from untreated mice (data not shown). Furthermore, TILs from 33D1 ${ }^{+}$DC-deleted mice, treated with L-PAM or not, showed similar NK cytotoxicity, from which the difference in E.G7-OVA tumor growth between the two groups should not be mediated (Fig. 6c, e). These findings suggest that selective stimulation of innate DEC-205 ${ }^{+}$DCs may generate acquired epitope-specific class I MHC molecule-restricted conventional $\mathrm{CD}^{+}$CTLs against already established tumors when they are slightly attacked in vivo with a very small amount of anticancer drugs, such as L-PAM.

We then tried to confirm the effect of L-PAM treatment on the induction of epitope-specific $\mathrm{CD} 8^{+} \mathrm{CTL}$ s using B16OVA. However, because B16-OVA was far more resistant to anticancer drugs such as L-PAM than E.G7-OVA, we needed more than $20 \mathrm{mg} / \mathrm{kg}$ to see a similar suppressive effect as has required for E.G7-OVA shown in Fig. 6c (light gray bar and black bar on day 13) and such a high amount of L-PAM treatment caused profound damage to the experimental mice, from which we could not obtain sufficient number of lymphocytes to analyze epitope specificity (data not shown).

Nevertheless, the fact that epitope-specific CD $8^{+}$CTLs for B16-OVA were seen in TILs from LPS-stimulated 33D $1^{+}$DC-deleted mice (Fig. 6b) strongly suggest that the strategy for selective stimulation of innate DEC- $205^{+}$DCs seems to provide a better way for controlling those cancer drug-resistant tumors.

\section{Discussion}

Recent reports indicate that two major distinct DC subsets control antigen presentation in vivo in mice [7]; 33D1- and DEC- $205^{+}$DC. In the present study, we determined the tissue distribution of these DCs using each-specific $\mathrm{mAb}$ and found that $33 \mathrm{D} 1^{+} \mathrm{DCs}$ are seemingly equally distributed in both systemic and local tissues, while DEC- $205^{+}$DCs are predominantly arranged in systemic compartments rather than local intraepithelium of the small intestine in C56BL/6 mice. Further studies are required to understand the reason for such unbalanced tissue distribution of two distinct DC subsets, particularly in the local surface area where numerous pathogens will be encountered externally and various carcinomas will be produced internally. From our observation, more DEC-205 ${ }^{+}$DCs are arranged in the spleen than in the intraepithelial compartment. Indeed, compatible with our findings, it has recently been reported that $\mathrm{CD} 11 \mathrm{c}^{+} \mathrm{DEC}-205^{+} \mathrm{DCs}$ were abundant in the white pulp of the human spleen [20].

Using anti-33D1-specific mAb, we have successfully established 33D $1^{+}$DC-deficient mice, in which DEC-205 ${ }^{+}$ DCs are predominantly distributed. Trumpfheller et al. have recently reported that DEC- $205^{+}$DCs induce a large number of Th1 type CD4 ${ }^{+} \mathrm{T}$ cells through TLR signaling if DEC- $205^{+}$DCs are stimulated by poly(I:C) [8]. On the basis of their findings, we injected $33 \mathrm{D} 1^{+}$DC-depleted mice to stimulate the remaining DEC-205 ${ }^{+}$DCs either with LPS (ligand for TLR4) or poly(I:C) (ligand for TLR3) [6]. Unexpectedly, higher in vivo production of IL-12, but not IL-10 was induced in $33 \mathrm{D}^{+}$DC-depleted mice when they were stimulated with LPS rather than with poly(I:C) (Fig. 2). To eliminate the possibility that other batches of poly(I:C) may have a more potent effect on $33 \mathrm{D} 1^{+} \mathrm{DC}$ depleted mice for IL-12 production, we are currently testing various lots of poly(I:C) to confirm the discrepancy, which may be generated by internal unbalanced DC dominancy caused by the depletion of 33D1 ${ }^{+}$DCs.

Moreover, based on our recent findings [11], we injected $33 \mathrm{D} 1^{+}$DC-depleted mice twice with LPS at weekly intervals, $100 \mu \mathrm{g}$ on day 3 and $50 \mu \mathrm{g}$ on day 10 after tumor implantation and observed the apparent inhibition of already established B16-F10 growth in vivo (Fig. 3b), which may have been caused by tumor-infiltrating $\mathrm{CD} 8^{+} \mathrm{T}$ lymphocytes seen in tissue specimens. These results suggest that in vivo production of IL-12 in $33 \mathrm{D} 1^{+} \mathrm{DC}$-depleted mice via LPS stimulation might induce internal Th1 dominancy, which may activate $\mathrm{CD} 8^{+}$tumor-specific CTLs and induce the suppression of implanted tumor growth in the dermis. In general, such activated $\mathrm{CD} 8^{+}$CTLs may recognize either mutated or non-mutated TAA that often contain specific CTL epitopes in conjunction with MHC class I molecules and eliminate tumors in the implanted region [21].

In contrast, the percentage of $\mathrm{NK} 1.1^{+} \mathrm{CD} 3^{-} \mathrm{NK}$ cells in the lung tissues of LPS-stimulated $33 \mathrm{D} 1^{+} \mathrm{DC}$-deleted mice, in which metastasis development was apparently suppressed, were markedly increased although the infiltration of $\mathrm{CD}^{+} \mathrm{T}$ cells was not observed. These results indicate that lung metastasis of B16-F10 melanoma seems to be mainly suppressed by NK cells that might also be activated by IL-12 secreted via LPS stimulation. Indeed, it has been reported that metastasis was greatly enhanced by NK cell depletion in DC-activated mice [22] and we have confirmed the above findings by NK cell depletion experiments (Fig. 5). On the basis of our findings, we are currently investigating the difference in class I MHC molecule expression between the original tumor and tumors obtained from the metastatic region. Taken together, upon the stimulation of 33D $1^{+}$DC-deleted mice with LPS, the remaining DEC- $205^{+}$DCs may secrete IL-12, by which both $\mathrm{CD} 8^{+}$ CTLs and NK cells are activated without co-administration of tumor antigens, and the former activated CTLs seems to inhibit implanted tumor growth and the latter activated NK cells may suppress tumor metastasis.

Our findings suggest that the stimulation of DEC-205 DCs with a TLR ligand, such as LPS, in vivo is sufficient to 
activate both tumor antigen-specific $\mathrm{CD} 8^{+} \mathrm{CTLs}$ at the tumor implanted site and NK cells in metastatic regions at the same time even in the absence of externally added tumor antigens. Activated DEC- $205^{+}$DCs may take up tumor antigens from tumor cells and cross-present tumorderived epitopes in association with class I MHC molecules of their own to prime epitope-specific $\mathrm{CD}^{+} \mathrm{CTLs}$ in vivo that can attack already established tumors. Although the precise mechanism remains to be investigated, such selectively stimulated DEC-205 ${ }^{+}$DCs appear also to activate NK cells that prevent tumor metastasis. Indeed, very recently, Sancho et al. [9] reported the usefulness of targeting DEC-205 ${ }^{+}$DCs with DNGR-1.

We have not confirmed the actual effector cells involved in the regression of the implanted tumors such as Hepa1-6 hepatoma and B16-F10 melanoma cells, on which downmodulated class I MHC molecules are sometimes expressed, and thus they might be targets for activated NK cells. Therefore, in order to confirm whether the cells involved in tumor regression are actually class I MHC molecule-restricted epitope-specific conventional $\mathrm{CD}^{+} \mathrm{CTLs}$ in this system, we conducted similar experiments using syngeneic E.G7-OVA and B16-OVA tumor cells that should be eliminated by $\mathrm{CD}^{+}$CTLs recognizing the known CTL epitope (SIINFEKL) presented by $\mathrm{K}^{\mathrm{b}}$ class I MHC molecules rather than by NK cells. In comparison with other syngeneic tumors, the regression of implanted E.G7-OVA in $33 \mathrm{D} 1^{+}$DC-deleted mice was almost unchanged by two injections of LPS. Nevertheless, ip inoculation of a mouse with L-PAM at a very low unaffected dose 10 days after implantation of E.G7-OVA resulted in marked reduction of the implanted EG7-OVA. In regressed tumors, we have observed an increased number of $\mathrm{CD} 8^{+}$ $\mathrm{H}-2 \mathrm{~K}$ /OVA tetramer-positive cells showing marked epitope-specific cytotoxic activities. These results indicate that selective stimulation of DEC-205 ${ }^{+}$DCs in vivo may generate acquired epitope-specific class I MHC moleculerestricted conventional $\mathrm{CD} 8^{+} \mathrm{CTLs}$ against already established tumors, such as E.G7-OVA expressing class I MHC when they are slightly attacked with a very small amount of anticancer drugs, such as L-PAM. However, as shown with B16-OVA, selective stimulation of innate DEC- $205^{+}$DCs appears superior for controlling cancer drug-resistant tumors instead of a high dose of anticancer drugs.

Taken together, the findings of the present study suggest the importance and effectiveness of selective targeting of a specific subset of innate DCs, such as DEC-205 ${ }^{+}$ DCs, together with very small doses of anticancer drugs against established tumors to activate functional acquired MHC-I-associated effectors, such as both $\mathrm{CD} 8^{+}$CTLs and $\mathrm{NK}$ cells in vivo without co-administration of tumor epitope antigens and provide a new direction for tumor immunotherapy.
Acknowledgments This work was supported in part by Grants from the Ministry of Education, Science, Sport, and Culture, from the Ministry of Health and Labor and Welfare, Japan, and from the Japanese Health Sciences Foundation, and by the Promotion and Mutual Aid Corporation for Private Schools of Japan.

Open Access This article is distributed under the terms of the Creative Commons Attribution Noncommercial License which permits any noncommercial use, distribution, and reproduction in any medium, provided the original author(s) and source are credited.

\section{References}

1. Takahashi H, Nakagawa Y, Yokomuro K, Berzofsky JA (1993) Induction of $\mathrm{CD}^{+}$cytotoxic $\mathrm{T}$ lymphocytes by immunization with syngeneic irradiated HIV-1 envelope derived peptide-pulsed dendritic cells. Int Immunol 5(8):849-857

2. Takahashi H (2003) Antigen presentation in vaccine development. Comp Immunol Microbiol Infect Dis 26(5-6):309-328

3. Bevan MJ (1976) Cross-priming for a secondary cytotoxic response to minor $\mathrm{h}$ antigens with $\mathrm{H}-2$ congenic cells which do not cross-react in the cytotoxic assay. J Exp Med 143(5):1283-1288

4. Melief CJ (2003) Mini-review: regulation of cytotoxic T lymphocyte responses by dendritic cells: peaceful coexistence of crosspriming and direct priming? Eur J Immunol 33(10):2645-2654

5. Takahashi H, Takeshita T, Morein B, Putney S, Germain RN, Berzofsky JA (1990) Induction of CD8 ${ }^{+}$cytotoxic T cells by immunization with purified HIV-1 envelope protein in ISCOMs. Nature 344(6269):873-875

6. Fujimoto C, Nakagawa Y, Ohara K, Takahashi H (2004) Polyriboinosinic polyribocytidylic acid [poly(i:C)]/TLR3 signaling allows class I processing of exogenous protein and induction of HIV-specific $\mathrm{CD}^{+}$cytotoxic $\mathrm{T}$ lymphocytes. Int Immunol 16(1):55-63

7. Dudziak D, Kamphorst AO, Heidkamp GF, Buchholz VR, Trumpfheller C, Yamazaki S, Cheong C, Liu K, Lee HW, Park CG, Steinman RM, Nussenzweig MC (2007) Differential antigen processing by dendritic cell subsets in vivo. Science 315(5808):107-111

8. Trumpfheller C, Caskey M, Nchinda G, Longhi MP, Mizenina O, Huang Y, Schlesinger SJ, Colonna M, Steinman RM (2008) The microbial mimic poly ic induces durable and protective $\mathrm{CD} 4^{+} \mathrm{T}$ cell immunity together with a dendritic cell targeted vaccine. Proc Natl Acad Sci U S A 105(7):2574-2579

9. Sancho D, Mourao-Sa D, Joffre OP, Schulz O, Rogers NC, Pennington DJ, Carlyle JR, Reis e Sousa C (2008) Tumor therapy in mice via antigen targeting to a novel, DC-restricted C-type lectin. J Clin Invest 118(6):2098-2110

10. Fernandez NC, Lozier A, Flament C, Ricciardi-Castagnoli P, Bellet D, Suter M, Perricaudet M, Tursz T, Maraskovsky E, Zitvogel L (1999) Dendritic cells directly trigger NK cell functions: cross-talk relevant in innate anti-tumor immune responses in vivo. Nat Med 5(4):405-411

11. Wakabayashi A, Nakagawa Y, Shimizu M, Moriya K, Nishiyama Y, Takahashi H (2008) Suppression of an already established tumor growing through activated mucosal CTLs induced by oral administration of tumor antigen with cholera toxin. J Immunol 180(6):4000-4010

12. Rowe DS, Fahey JL (1965) A new class of human immunoglobulins. I. A unique myeloma protein. J Exp Med 121:171-184

13. Wang X, Fjerdingstad H, Strom-Gundersen I, Benestad HB (1999) Maturation rate of mouse neutrophilic granulocytes: acceleration by retardation of proliferation, but no detectable influence from G-CSF or stromal cells. Stem Cells 17(5):253-264 
14. Calder CJ, Liversidge J, Dick AD (2004) Murine respiratory tract dendritic cells: Isolation, phenotyping and functional studies. J Immunol Methods 287(1-2):67-77

15. Takahashi H, Nakagawa $Y$, Leggatt GR, Ishida $Y$, Saito $T$, Yokomuro K, Berzofsky JA (1996) Inactivation of human immunodeficiency virus (HIV)-1 envelope-specific $\mathrm{CD} 8^{+}$cytotoxic T lymphocytes by free antigenic peptide: a self-veto mechanism? J Exp Med 183(3):879-889

16. Rotzschke O, Falk K, Stevanovic S, Jung G, Walden P, Rammensee HG (1991) Exact prediction of a natural T cell epitope. Eur J Immunol 21(11):2891-2894

17. Nakatsuka K, Sugiyama H, Nakagawa Y, Takahashi H (1999) Purification of antigenic peptide from murine hepatoma cells recognized by class-I major histocompatibility complex moleculerestricted cytotoxic T-lymphocytes induced with B7-1-gene-transfected hepatoma cells. J Hepatol 30(6):1119-1129

18. Ben-Efraim S, Bocian RC, Mokyr MB, Dray S (1983) Increase in the effectiveness of melphalan therapy with progression of MOPC-
315 plasmacytoma tumor growth. Cancer Immunol Immunother 15(2):101-107

19. Takesue BY, Pyle JM, Mokyr MB (1990) Importance of tumorspecific cytotoxic $\mathrm{CD} 8^{+} \mathrm{T}$-cells in eradication of a large subcutaneous MOPC-315 tumor following low-dose melphalan therapy. Cancer Res 50(23):7641-7649

20. Pack M, Trumpfheller C, Thomas D, Park CG, Granelli-Piperno A, Munz C, Steinman RM (2008) Dec-205/CD205 ${ }^{+}$dendritic cells are abundant in the white pulp of the human spleen, including the border region between the red and white pulp. Immunology 123(3):438-446

21. van den Broeke LT, Daschbach E, Thomas EK, Andringa G, Berzofsky JA (2003) Dendritic cell-induced activation of adaptive and innate antitumor immunity. J Immunol 171(11):5842-5852

22. Peron JM, Esche C, Subbotin VM, Maliszewski C, Lotze MT, Shurin MR (1998) Flt3-ligand administration inhibits liver metastases: role of NK cells. J Immunol 161(11):6164-6170 